\title{
A STUDY OF SERUM LIPOPROTEINS IN NORMAL AND ATHEROSCLEROTIC PATIENTS BY PAPER ELECTROPHORETIC TECHNIQUES
}

\author{
By WILLIAM P. JENCKS, MARION R. HYATT, MERA R. JETTON, THOMAS W. \\ MATTINGLY, AND E. L. DURRUM 1
(From the Department of Pharmacology, Walter Reed Army Institute of Research and the Department of Medicine, Walter Reed Army Hospital, Walter Reed Army Medical Center, Washington, D. C.)

(Submitted for publication December 5, 1955 ; accepted May 17, 1956)

The existence of a specific abnormality of lipid metabolism in patients with atherosclerosis has been suggested by recent studies which have shown that the concentration of certain serum lipoproteins in patients with coronary disease is statistically different from that found in "normal" individuals. Gofman and his co-workers (1) found in such patients an elevation of a beta lipoprotein sub-fraction defined by ultracentrifugal flotation rates between Sf 10 and 20. Russ, Eder, and $\operatorname{Barr}(2,3)$ measured the cholesterol content of precipitated serum lipoprotein fractions and found that the total beta lipoprotein fraction was increased in serum from a group of atherosclerotic patients as compared to a control group made up largely of hospital personnel. Similar results have been obtained by Nikkilä (4), who measured the cholesterol content of electrophoretically separated protein fractions, and by Antonini et al. (5) and Kroetz and Fischer (6) who measured lipoprotein concentration in terms of the lipid dye binding of serum proteins separated by paper electrophoresis.

Studies on the validity and reproducibility of two relatively simple methods for the estimation of electrophoretically separated serum lipoproteins by measurement of their cholesterol content and dye binding capacity have recently been reported from this laboratory $(7,8)$. These methods are not subject to significant error due to loss of lipoprotein bound dye during alcohol rinsing, oxidation of cholesterol, or tailing of lipoprotein during electrophoresis similar to that found with albumin. The studies reported here were carried out in order to test the large scale application of these methods, to compare the results of the two methods with each other and with ultracentrifugal methods, and to confirm further the association of

1 Present address : Department of Pharmacology, Stanford University Medical School, Clay \& Webster Sts., San Francisco 15, California. serum lipoprotein abnormalities with atherosclerosis, making use of both healthy and hospitalized control groups to lessen the possibility that any observed abnormalities might be the result of illness, medication, diet, or restricted activity rather than of atherosclerosis per se.

\section{MATERIALS AND METHODS}

Separation and analysis of serum proteins and lipoproteins was carried out as previously described (7-10). Lipid material with zero mobility on paper, consisting of chylomicrons and adsorbed beta lipoprotein, was included in the beta lipoprotein fraction. A small amount of lipid staining material with a mobility slightly greater than beta lipoprotein was occasionally observed. Unpublished experiments from this laboratory have confirmed the finding of Ray, Davisson, and Crespi (11) that isolated beta lipoproteins are oxidized during dialysis and have also shown that this may occur during paper electrophoresis, resulting in an increase in the mobility of beta lipoprotein to that of an alpha ${ }_{2}$ or even alpha ${ }_{1}$ globulin. Although this may be prevented by ethylenediaminetetraacetic acid and is normally prevented in whole serum by the presence of albumin, the possibility that the observed lipid staining material may be a fraction of beta lipoprotein of slightly increased mobility as a result of oxidation (12) or binding of traces of fatty acid anions (13) has not been ruled out. This possibility is supported by the fact that this fraction usually occurs as a shoulder on the beta lipoprotein peak rather than as a separate fraction and by the wide range of mobility, ranging from beta to alpha $a_{2}$ globulin, observed for the main lipoprotein band of many pathological sera. For these reasons, the distinguishing of a separate alpha lipoprotein fraction did not appear to be warranted on the basis of evidence so far available and was not attempted in this study.

Oil Red O staining of separated lipoproteins was carried out with Lot No. 15448 (National Aniline Division, Allied Chemical and Dye Corp.). A rough, empirical estimate of the absolute concentrations of alpha and beta lipoproteins was obtained from this procedure by comparison of the dye uptake by lipoprotein to the dye uptake of a standard of $125 \mu \mathrm{g}$. of triolein applied to the paper strip in $0.025 \mathrm{cc}$. of chloroform and stained at the same 


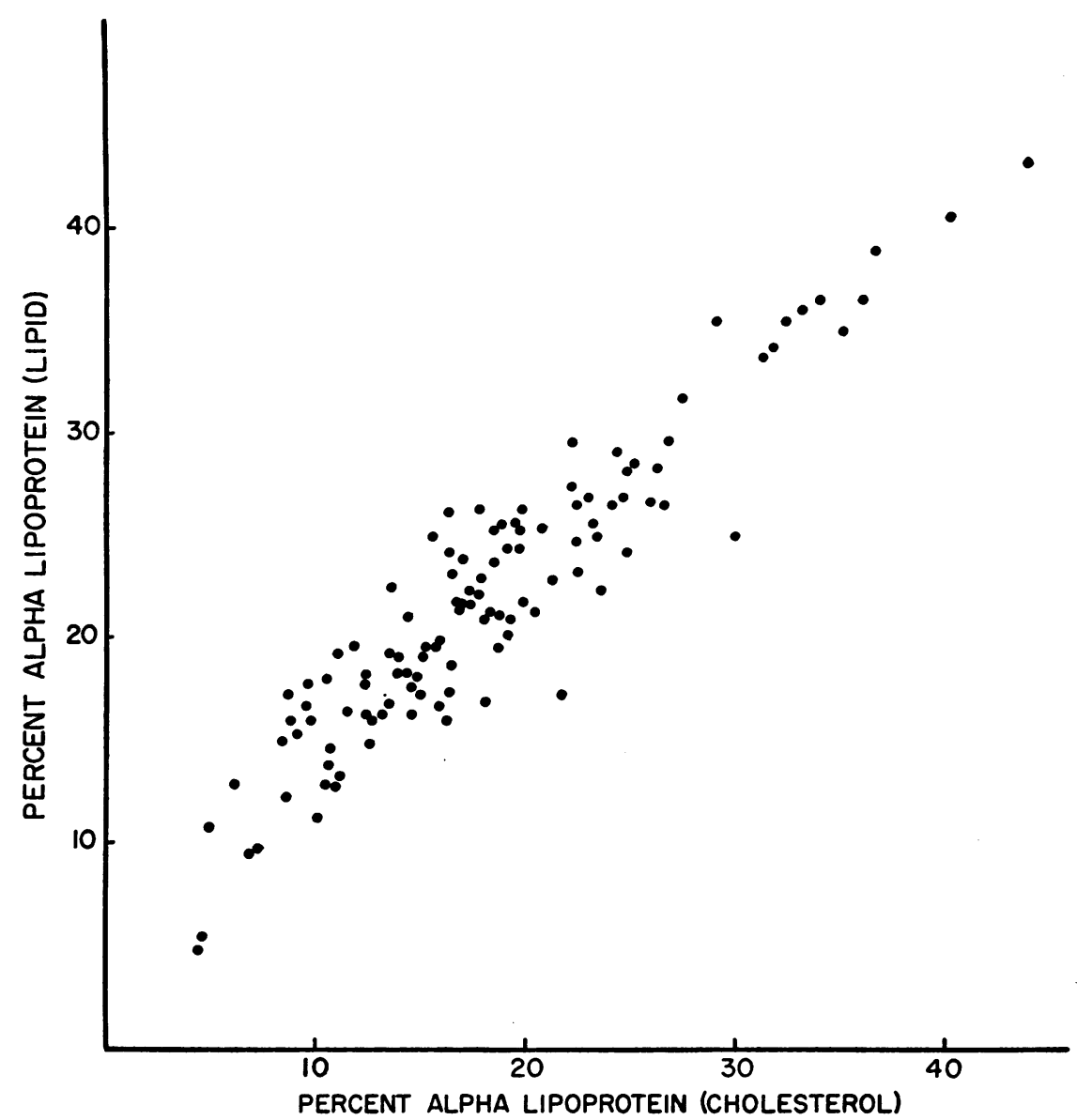

Fig. 1. The Relationship between the Fraction of the Total Serum Cholesterol Found in the Alpha Lipoprotein Fraction and the Fraction of the Total Lipid Dye Binding Capacity Found in the Alpha Lipoprotein Fraction as measured by Duplicate Paper Electrophoretic Determinations on 126 Normal and Abnormal Sera

time as the lipoprotein. Preliminary experiments indicated that the use of such a triolein standard resulted in as good or better agreement between replicate serum analyses as did the use of a standard serum (8).

Lipoprotein concentrations estimated by this method are reported arbitrarily in terms of "triolein units" which represent the amount of triolein in $\mathrm{mg}$. per $100 \mathrm{cc}$. which would take up the same amount of dye as was taken up by the sample analyzed. It is not possible to express lipoprotein concentration as measured by this method in terms of absolute concentration because of the variation in the dye uptake of different lipids.

The sum of the alpha and beta lipoprotein cholesterol values after electrophoresis and elution was compared to the results of total cholesterol determinations by the Sperry and Webb modification of the SchoenheimerSperry procedure (14) on 126 normal and abnormal sera. The mean values for total cholesterol obtained by the two methods agreed within 2.2 per cent (standard deviation 8 per cent) indicating that no appreciable systematic er- ror was influencing the lipoprotein cholesterol elutions and determinations.

Scanning of electrophoretically separated serum proteins stained with bromphenol blue was carried out with an automatically recording instrument (15) using tungsten light passed through a Bausch and Lomb $604 \mathrm{~m} \mu$ second order interference filter, a Corning 3385 cut-off filter and a $2-\mathrm{mm}$. slit. The albumin values were corrected for the non-linear relationship between scanner response and high concentrations of dye on paper by reference to a standard curve obtained by elution of dye from the albumin and globulin fractions of normal and pathological sera. No correction was made for the 3 to $\mathbf{5}$ per cent loss of albumin due to adsorption on the paper (10) and no attempt was made to convert results to other units than dye binding; for this reason the values for protein distribution obtained by this method are not the same as those obtained by the moving boundary method when measured by increment in refractive index. 


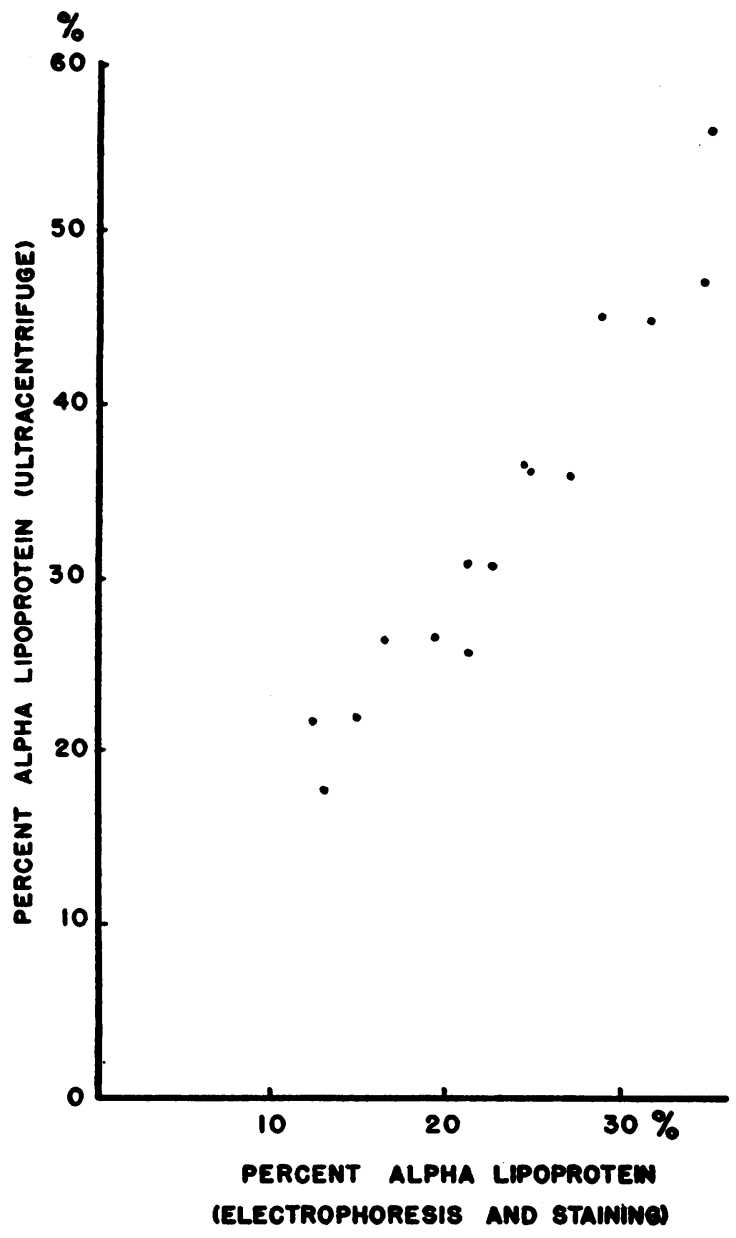

Fig. 2. A Comparison of the Ratio of Alpha to Total Serum Lipoprotein as Measured by Paper Electrophoresis and Lipid Dye Binding to the Ratio OF Alpha $\left(\mathrm{SF}_{1 . n}\right.$ 0-20) to Total (SFi.n 0-250) SERUM LIPOPROTEIN AS MEASUREd BY ULTRACENTRIFUgation AND REFRACTIVE INDEX INCREMENT

Total protein concentration was determined by the biuret method (16) using as a standard a solution of bovine albumin which was calibrated by micro Kjeldahl determination of nitrogen using the factor 6.25 to convert nitrogen to protein concentration.

Ultracentrifugal analysis of lipoproteins by flotation at a density of 1.063 was carried out as described (17). Ultracentrifugation at a density of 1.21 was carried out by a modification of the methods of Lewis and Page (18), de Lalla and Gofman (19) and Boyle, Bragdon, and Brown (20).2 Preparative ultracentrifugation was carried out in a $\mathrm{KBr}-\mathrm{NaCl}$ medium of density 1.21 at $16^{\circ} \mathrm{C}$. for 18 hours at $52,640 \mathrm{rpm}$ in the $\mathrm{J}$ rotor of the Spinco Model E ultracentrifuge. The top fraction was

2 We are grateful to Dr. Edwin Boyle for advice on the analysis of lipoproteins at a density of 1.21 and for unpublished details for the construction of a tube slicer. removed with a tube slicer and analyzed at $56,100 \mathrm{rpm}$ in a model $\mathrm{AD}$ analytical rotor using a 6-minute acceleration time which was considered equivalent to two minutes at full speed. Alpha 1 lipoprotein concentration was calculated from the refractive index increment of lipoproteins of uncorrected $\mathrm{Sf}_{1 . n} \mathrm{O}-20$ in the 40 -minute picture and beta lipoprotein concentration from $\mathrm{Sf}_{1 . n} 20-250$ in the films taken 2 and 12 minutes after reaching full speed. No separate peak was found in these sera at Sf 20-25 and any lipoprotein found in this range was included as a part of the beta fraction.

All analyses on each serum specimen were completed within 30 days. Control experiments indicated that in the absence of gross contamination by microorganisms no change in lipoprotein concentration occurred on storage of serum at 1 to $3^{\circ} \mathrm{C}$. for this period of time. No attempt was made to control the time of day at which blood specimens were drawn from either the control or experimental groups. If more than one specimen from the same patient was analyzed, the results of the individual determinations were averaged so that no patient was represented more than once in the statistical evaluation of the data.

Statistical comparisons were carried out by the " $t$ test," and significances are reported in terms of "p," the probability that the observed difference between two groups is due to chance alone (21). All comparisons were checked by analysis of variance and the "F test" and found to have the same degree of significance as with the "t test."

\section{RESULTS}

\section{Interrelationship of methods}

In order to compare the results of the lipid staining with the cholesterol elution procedure for measuring the concentration of separated lipoproteins, analyses were carried out in duplicate by both of these methods on 126 normal and abnormal sera. The results are shown in Figure 1, expressed as the per cent of the total stainable lipid or cholesterol found in the alpha lipoprotein fraction of each serum. The two methods gave comparable results, with some deviation from linearity in their relationship because of the nonlinear dye uptake of high concentrations of beta lipoprotein (8). The fact that higher values are obtained for the per cent alpha lipoprotein in terms of stainable lipid than in terms of cholesterol content reflects the different composition of these lipoproteins; however, the fact that the results of the empirical and chemically non-specific staining procedure (which does not stain pure cholesterol) are at all comparable to those obtained by cholesterol analysis indicates a considerable degree of 
constancy in the composition of these lipoproteins from one serum to another. Comparisons of the absolute amounts of dye uptake with the cholesterol content of the individual lipoprotein fractions confirmed these conclusions, although these curves showed a slightly greater scatter than the curve of lipoprotein distribution because the staining method is more accurate as a measure of lipoprotein distribution than of absolute lipoprotein concentration (8).

A similar comparison between the results of the staining method and results obtained by ultracentrifugation at a density of 1.21 is shown in Figure 2. Comparable results were obtained for the ratio of alpha to total lipoprotein as measured by these two methods. The higher values for this ratio obtained by refractive index measurement in the ultracentrifugal procedure may be attributed to the relatively high ratio of protein to lipid in alpha lipoprotein (12). Again, the results suggest that, at least in the 16 sera examined, the composition of the alpha and beta lipoproteins does not vary greatly from one serum to another.
Lipoprotein analyses of sera from control and atherosclerotic groups

Analyses of lipoprotein concentration and distribution by both the lipid staining and cholesterol elution procedures were carried out on a group of 77 patients with presumed atherosclerosis and compared to the results obtained on sera from a group of 68 healthy controls and 65 patients who were hospitalized for reasons other than vascular disease or other diseases known to be associated with abnormalities in lipid or lipoprotein metabolism. The group of "normal" controls consisted of 68 male Army officers, mostly over the age of 45, who had been found to have no clinical evidence of cardiovascular or other disease on physical examination. The hospitalized patients were selected at random from those hospital admissions in the same age range as the atherosclerotic group who did not have vascular, hepatic, renal, thyroid or diabetic disease. The presumably atherosclerotic group consisted of male Army personnel with clinical diagnoses of myocardial infarction supported by electrocardiographic evidence.

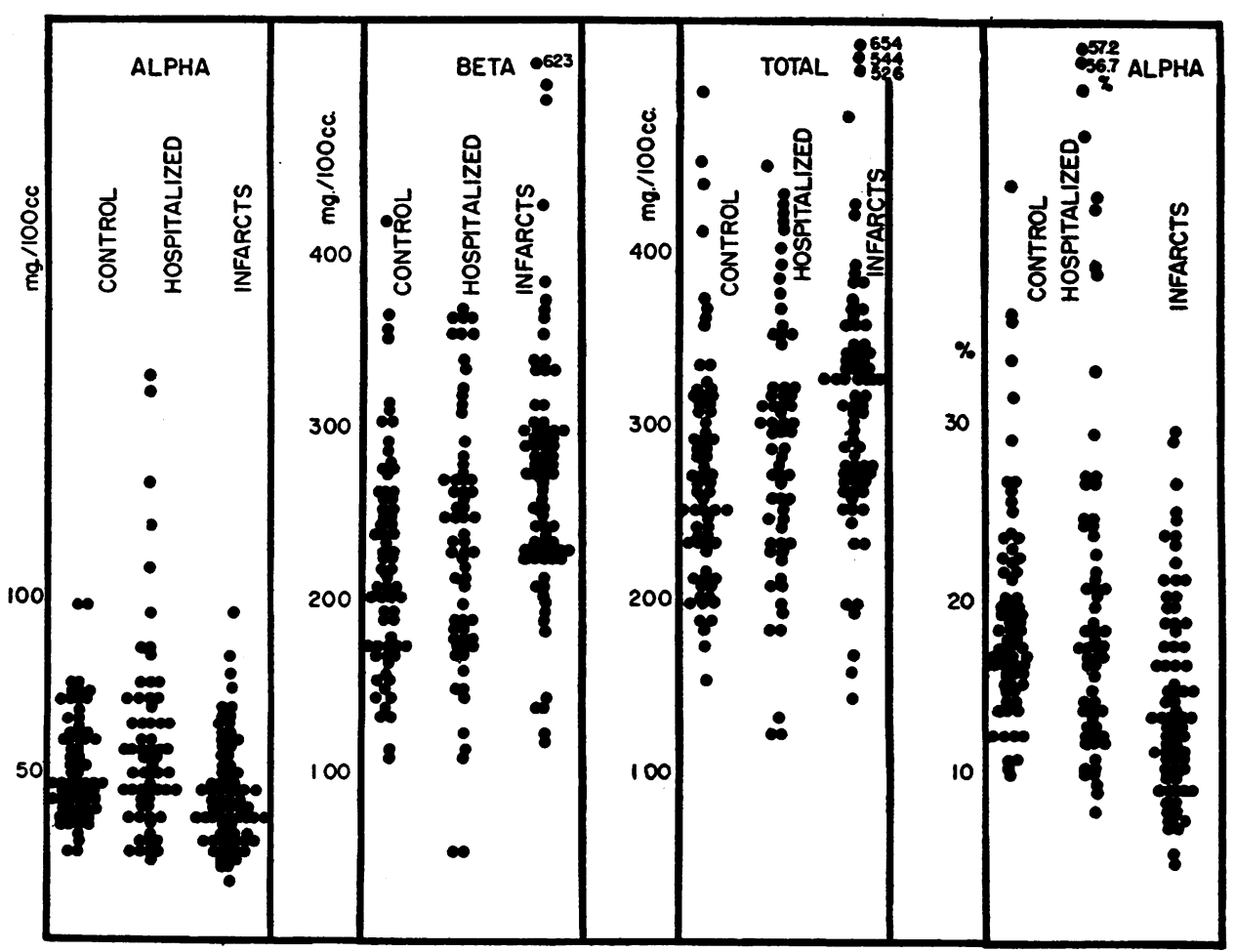

Fig. 3. Scatter Diagrams Showing the Concentration and Distribution of Serum Lipoprotein Cholesterol in Normal and Hospitalized Males aNd in Males with a History OF MYOCARDIAL INfarction 


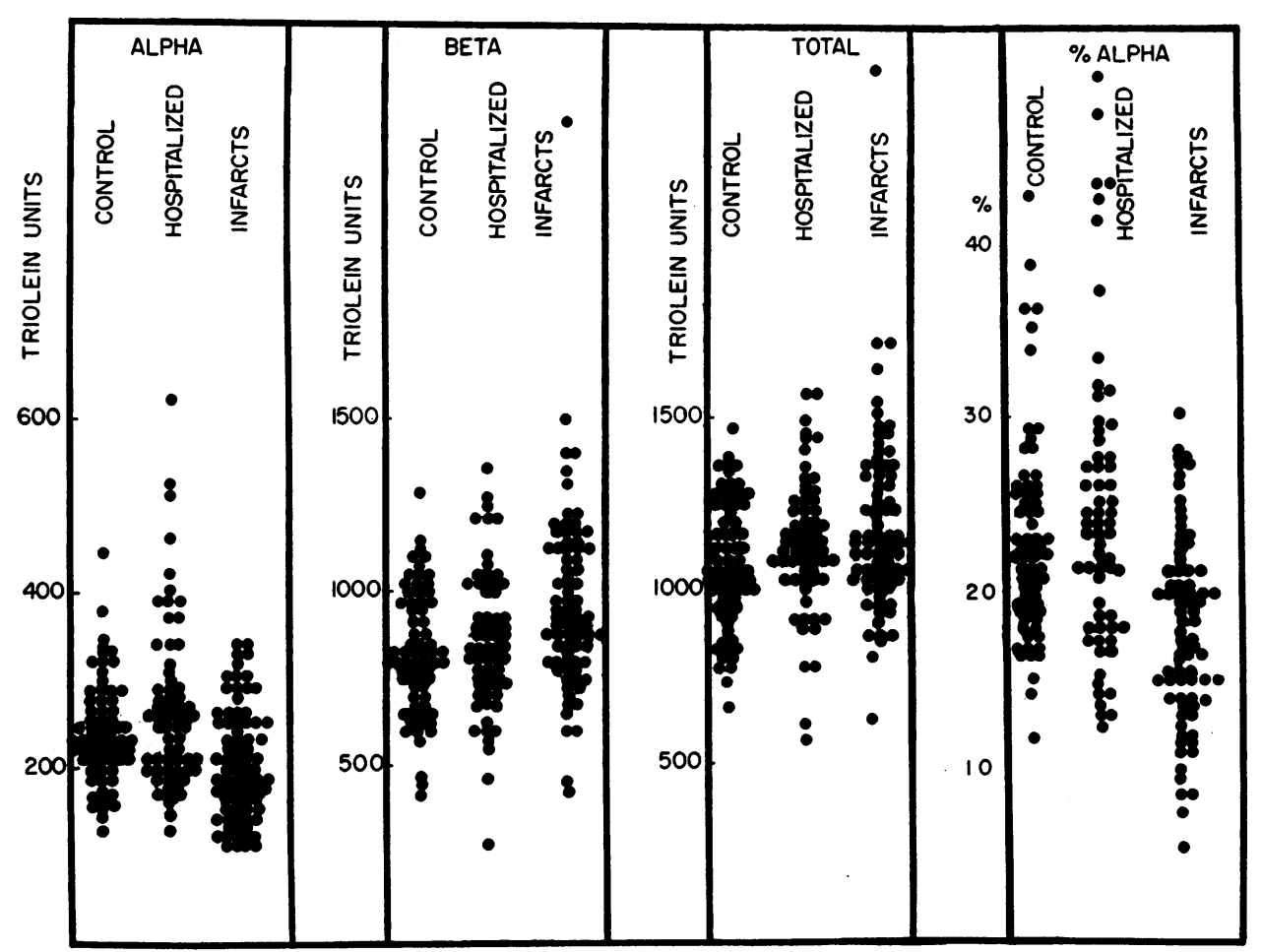

Fig. 4. Scatter Diagrams Showing the Concentration and Distribution of Lipids in the Skrum Lipoproteins of Normal and Hospitalized Males and in Males with a History of Myocardial Infarction as Measured by Staining with the Lipid Dye Oil Red O

The mean ages of the three groups, given in Table I, are closely similar; the age distributions were also similar except that the group of "normal" Army officers fell within a somewhat narrower age range than the other two groups. No relationship of lipoprotein levels to age was apparent in these samples of relatively restricted age range.

The data obtained from these groups are summarized in Table $I$ and in Figures 3 and 4 . A comparison was made first of the results obtained with the two control groups: the normal and the hospitalized. There was no significant difference in the concentration or distribution of serum lipoproteins in these two groups except for a slight elevation of alpha lipoprotein in the hospitalized group, as measured by dye binding. As shown in the scatter diagram of Figure 4, this elevation is largely due to a few high values and it is statistically only "probably significant" at the 5 per cent level. Inspection of the discharge diagnoses of the patients in the hospitalized group revealed no correlation of lipoprotein abnormalities with the diag- nosis or the severity of disease, with the exception of a questionable tendency towards elevation of alpha lipoprotein concentration in patients with prostatic disease. It may be concluded that there are no marked differences in lipoprotein concentration and distribution associated with differences between normal and hospitalized patients subject to the limitations of selection described above. The data from these two control groups were, therefore, pooled for comparison with the data from patients with myocardial infarction. (Calculations of the apparent significance of the differences between the group with myocardial infarctions and each of the above control groups separately gave results which were very similar to those reported below for the pooled data, with the exception of the total cholesterol and total lipid concentrations which were not significantly different in the hospitalized and infarct groups; however, since such calculations require the use of the same group for more than one comparison, they are not independent comparisons and are, therefore, not reported in detail.) 
The data obtained on patients with myocardial infarctions (Table I) indicate that this group differs from the pooled control group in all measures of lipid and lipoprotein concentration and distribution that were studied, regardless of the method used for analysis. The differences are all statistically significant at the 0.1 per cent level except for the increase in total cholesterol which is significant only at the 1.0 per cent level and the increase in total lipid which is probably significant at the 5 per cent level. It is evident from the results of both the cholesterol and the staining methods that the concentration of alpha lipoprotein is decreased and the concentration of beta lipoprotein is increased in the coronary group. The ratio of alpha to total lipoprotein, or "per cent alpha," which is a function of both of these changes, therefore shows an even greater difference between the groups than either the alpha or the beta fraction alone. The distribution and overlap of the individual values obtained in each group are shown in Figures 3 and 4.

A quantitative measure of the relative effective- ness of the different measurements made on sera from control and atherosclerotic groups in differentiating these groups from each other was obtained by calculation of the value $r^{2}$ from the formula $r^{2}=\frac{t^{2}}{n-2+t^{2}}(21$, p. 193).8 The value so obtained represents the fraction of the total variation in a set of measurements which is due to differences between the groups rather than to random variation within each group; thus, a large value for $\mathrm{r}^{2}$ indicates that a particular measurement differentiates two groups effectively, while a small value indicates that random variation of that measurement is large compared to the difference between the two groups. The relatively low values for $\mathrm{r}^{2}$ shown in Table I reflect the overlap of measurements in the control and atherosclerotic groups. However, it is evident that measurement of either alpha or beta lipoprotein concentration is a considerably better means for differentiating these

${ }^{8}$ We are greatly indebted to Dr. Ardie Lubin of the Department of Psychology, Walter Reed Army Institute of Research, for suggesting this method of analysis.

TABLE I

Lipoprotein concentration and distribution in normal and hospitalized males and in patients with a diagnosis of myocardial infarction

\begin{tabular}{|c|c|c|c|c|c|c|c|c|c|c|}
\hline & \multirow[b]{2}{*}{$\mathbf{n}$} & \multirow[b]{2}{*}{ Age } & \multicolumn{4}{|c|}{$\begin{array}{c}\text { Lipoprotein cholesterol } \\
(m g . / 100 ~ c c .)\end{array}$} & \multicolumn{4}{|c|}{$\begin{array}{c}\text { Lipoprotein dye-binding } \\
\text { triolein units } \\
(m g . / 100 \text { cc.) }\end{array}$} \\
\hline & & & Alpha & Beta & Total & $\begin{array}{c}\% \\
\text { Alpha } \\
\end{array}$ & Alpha & Beta & Total & $\begin{array}{c}\% \\
\text { Alpha } \\
\end{array}$ \\
\hline \multicolumn{11}{|l|}{ Normal: } \\
\hline $\begin{array}{l}\text { Mean } \\
\text { Std. deviation }\end{array}$ & 68 & 47.8 & $\begin{array}{l}51 \\
16\end{array}$ & $\begin{array}{r}223 \\
63\end{array}$ & $\begin{array}{r}274 \\
68\end{array}$ & $\begin{array}{r}19.4 \\
6.6\end{array}$ & $\begin{array}{r}246 \\
58\end{array}$ & $\begin{array}{l}840 \\
179\end{array}$ & $\begin{array}{r}1,086 \\
183\end{array}$ & $\begin{array}{r}22.7 \\
6.0\end{array}$ \\
\hline \multicolumn{11}{|l|}{ Hospitalized: } \\
\hline $\begin{array}{l}\text { Mean } \\
\text { Std. deviation }\end{array}$ & 65 & 50.9 & $\begin{array}{l}58 \\
29\end{array}$ & $\begin{array}{r}233 \\
75\end{array}$ & $\begin{array}{r}291 \\
76\end{array}$ & $\begin{array}{l}21.0 \\
11.4\end{array}$ & $\begin{array}{r}273 \\
97\end{array}$ & $\begin{array}{l}866 \\
315\end{array}$ & $\begin{array}{r}1,140 \\
296\end{array}$ & $\begin{array}{r}24.4 \\
8.5\end{array}$ \\
\hline \multicolumn{11}{|l|}{ Comparison } \\
\hline $\begin{array}{l}\text { "t" } \\
\text { Significance (p) }\end{array}$ & & & $\begin{array}{r}1.64 \\
\text { None }\end{array}$ & $\begin{array}{r}0.80 \\
\text { None }\end{array}$ & $\begin{array}{r}1.35 \\
\text { None }\end{array}$ & $\begin{array}{r}0.97 \\
\text { None }\end{array}$ & $\begin{array}{r}2.02 \\
<5 \%\end{array}$ & $\begin{array}{r}0.62 \\
\text { None }\end{array}$ & $\begin{array}{r}1.27 \\
\text { None }\end{array}$ & $\begin{array}{l}1.18 \\
\text { None }\end{array}$ \\
\hline \multicolumn{11}{|l|}{$\begin{array}{l}\text { Pooled normal and } \\
\text { hospitalized } \\
\text { controls: }\end{array}$} \\
\hline $\begin{array}{l}\text { Mean } \\
\text { Std. deviation }\end{array}$ & 133 & 49.3 & $\begin{array}{l}55 \\
24\end{array}$ & $\begin{array}{r}228 \\
69\end{array}$ & $\begin{array}{r}282 \\
72\end{array}$ & $\begin{array}{r}20.2 \\
9.3\end{array}$ & $\begin{array}{r}259 \\
80\end{array}$ & $\begin{array}{l}853 \\
254\end{array}$ & $\begin{array}{r}1,112 \\
245\end{array}$ & $\begin{array}{r}23.6 \\
7.4\end{array}$ \\
\hline \multicolumn{11}{|l|}{ Infarcts : } \\
\hline $\begin{array}{l}\text { Mean } \\
\text { Std. deviation }\end{array}$ & 77 & 50.4 & $\begin{array}{l}43 \\
16\end{array}$ & $\begin{array}{r}273 \\
81\end{array}$ & $\begin{array}{r}316 \\
81\end{array}$ & $\begin{array}{r}14.3 \\
5.8\end{array}$ & $\begin{array}{r}208 \\
64\end{array}$ & $\begin{array}{l}986 \\
265\end{array}$ & $\begin{array}{r}1,195 \\
260\end{array}$ & $\begin{array}{r}17.9 \\
5.5\end{array}$ \\
\hline \multicolumn{11}{|l|}{ Comparison } \\
\hline $\begin{array}{l}\text { "t" } \\
\text { Significance (p) } \\
r^{2}\end{array}$ & & & $\begin{array}{r}3.85 \\
<0.1 \% \\
0.067\end{array}$ & $\begin{array}{c}4.27 \\
<0.1 \% \\
0.081\end{array}$ & $\begin{array}{l}3.10 \\
<1.0 \% \\
\mathbf{0 . 0 4 4}\end{array}$ & $\begin{array}{c}5.00 \\
<0.1 \% \\
0.107\end{array}$ & $\begin{aligned} 4.75 \\
<0.1 \% \\
0.098\end{aligned}$ & $\begin{aligned} 3.63 \\
<0.1 \% \\
0.060\end{aligned}$ & $\begin{array}{l}2.32 \\
<5 \% \\
0.025\end{array}$ & $\begin{aligned} 6.02 \\
<0.1 \% \\
0.148\end{aligned}$ \\
\hline
\end{tabular}


TABLE II

Average distance from the point of application to the center of the peaks of electrophoretically separated alpha and beta lipoproteins

\begin{tabular}{lcc}
\hline & \multicolumn{2}{c}{ Distance of migration } \\
\cline { 2 - 3 }$(\mathrm{cm})$. & \\
\cline { 2 - 3 } & Alpha & Beta \\
\hline Normal controls & 3.34 & 0.86 \\
Hospitalized & 3.15 & 0.86 \\
Infarcts & 3.24 & 0.85 \\
\hline
\end{tabular}

groups, regardless of whether the measurement is carried out by staining or cholesterol elution, than is measurement of either total cholesterol or total lipid. The ratio of alpha to total lipoprotein is, as might be expected, the best index of difference between the groups, since it reflects the differences in both alpha and beta lipoproteins.

A comparison of serum lipoprotein distributions at varying periods of time after myocardial infarction revealed some tendency towards an increase in the per cent alpha lipoprotein six months or more after an acute episode. The average value for the per cent of the total cholesterol in the alpha lipoprotein fraction of sera drawn within one month after an acute attack was 14.7 per cent, which was not significantly different from the value of 12.4 per cent obtained on sera drawn between one and six months after an attack. However, sera drawn over six months after an attack had an alpha lipoprotein fraction of 16.1 per cent which is probably significantly greater than the combined values for 0 to 6 months ( $p=<5$ per cent). Whether this increase indicates that the abnormality in lipoprotein distribution found in patients with myocardial infarction is a transient metabolic alteration which returns to normal with time or whether it is a result of selection due to death of those individuals with low values within a six-month period after their first infarction cannot be decided from these data. However, the second alternative appears somewhat more likely since after the first month, during which patients might be expected largely to recover from the acute effects of their illness, there is no increase, but actually a small decrease in the per cent alpha lipoprotein.

If the lipoproteins in atherosclerotics are qualitatively as well as quantitatively different from normal, one manifestation of this abnormality could be a shift in electrophoretic mobility. The mobility of the lipoproteins of the control and atherosclerotic groups was estimated by measuring the distance between the point of serum application and the peak of each stained lipoprotein fraction before elution. Such a procedure, while not very accurate in any single determination, should show any tendency towards abnormal mobility in a large group of samples. The results shown in Table II indicate that no such abnormality of lipoprotein mobility occurred in this group of patients.

The electrophoretic distribution of serum proteins expressed in terms of bromphenol blue dye binding capacity in normal, hospitalized and infarction groups is shown in Table III. The average concentration of albumin is slightly lower, and all of the globulin fractions are slightly higher in the hospitalized compared with the normal group. This relatively non-specific alteration in serum protein distribution is to be expected as a result of illness in this group of patients (22). The group of patients with myocardial infarction, on the other hand, shows only a very small decrease in albumin accompanied by a small generalized rise in the globulin fractions. It appears likely that this small change, if significant at all, is a non-specific response to illness and is in contrast to the abnormalities of lipoprotein distribution found in this group of patients, which were not found in the hospitalized group. These results may be compared to the results of other studies from this and other laboratories $(22,23)$ in which considerably more marked decreases in albumin concentration were observed in atherosclerotic patients. It seems likely that this difference may also be accounted for by differences in the degree of illness in the various groups: the group of atherosclerotic patients to be reported elsewhere were

TABLE III

Serum protein distribution in normal and hospitalised males
and in patients with myocardial infarction as
measured by paper electrophoresis


all hospitalized and many of them were critically ill.

In spite of the increased concentration of beta lipoprotein in the patients with coronary atherosclerosis, the relative concentration of beta globulin is not appreciably increased; the very small increase observed is accompanied by similar increases in the other globulins and may simply reflect the small fall in albumin concentration. Plots of alpha and beta lipoprotein against alpha $a_{1}$ and beta globulin concentrations respectively in each serum failed to reveal any relationship between lipoprotein and globulin concentration in either normal or abnormal sera. It was concluded that it was not possible to infer the presence of abnormal lipoprotein levels from the results of paper electrophoresis of serum without specifically measuring the concentrations of the lipoproteins (this may not necessarily be the case in moving boundary electrophoresis in which lipid makes a considerable contribution to the measured concentration of beta globulin, so that lipoprotein accounts for 15 to 30 per cent of the beta globulin peak in normal sera and up to 60 per cent in abnormal sera when measured by refractive index increment [18]). Since the lipoproteins represent only a small fraction of the total alpha and beta globulins of serum, it is also not possible to draw any conclusions about the ratio of lipid to protein in the lipoprotein molecules of atherosclerotic individuals from the type of data reported here.

\section{Comparison of ultracentrifugal with electropho- retic procedures in normal and atherosclerotic groups}

A comparison was made of the results obtained by analyzing 97 sera by ultracentrifugation at a density of 1.063 according to the technique developed by Gofman and his associates (1) with the results of analyses on the same sera by paper electrophoresis. In Figure 5 the concentration of the beta lipoprotein subfraction with uncorrected flotation rates of Sf 12-20 is plotted against the per cent of the total cholesterol in the alpha lipoprotein fraction, for each of the 68 normal and the 29 atherosclerotic (as judged by either myocardial infarction or angina pectoris) individuals in this group. No quantitative comparison of the relative

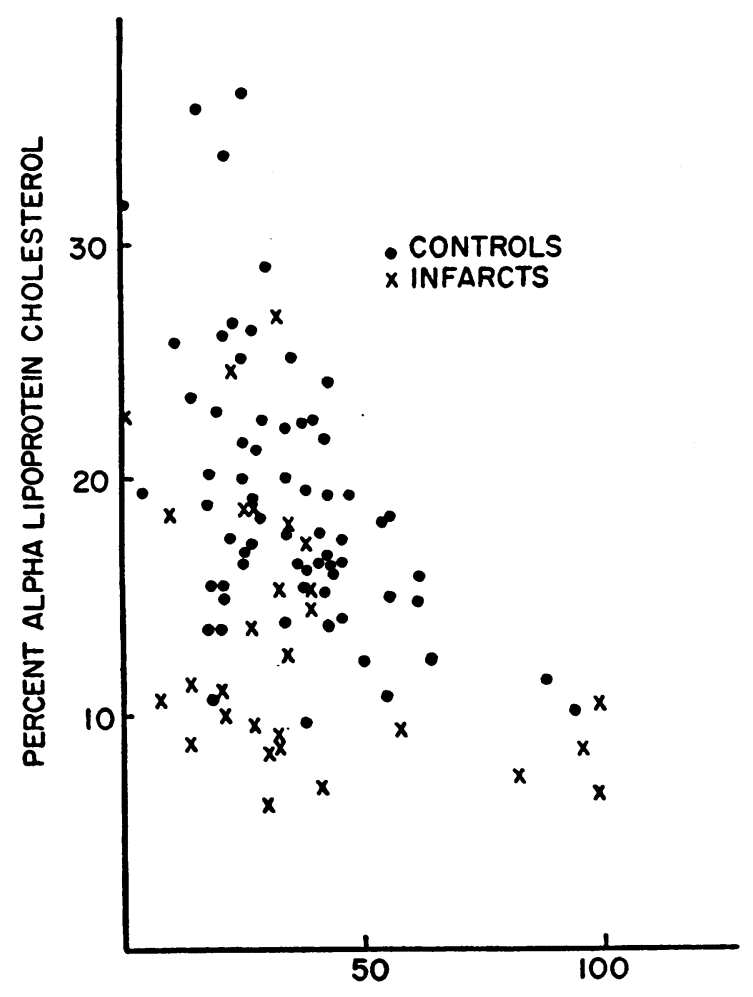

Sf 12-20 LIPOPROTEIN mg./100cc.

Fig. 5. The Concentration of Serum Lipoprotein with Flotation Rates of Sf 12-20 at a Density of 1.063 and the Per Cent of the Total Serum Cholesterol Found in the Alpha Lipoprotein Fraction in a Group of Normal Males and a Group of Males with a History of Myocardial Infarction or Angina PeCTORIS

effectiveness of the two procedures in segregating normal from atherosclerotic populations was attempted with this number of analyses, but it is quite apparent from inspection of the data that the electrophoretic procedure is considerably more effective than this particular ultracentrifugal measurement in this respect; i.e., although with both procedures there is a considerable overlap of the values for the normal and control groups, the per cent alpha lipoprotein cholesterol is much more often outside the normal range in atherosclerotic patients than is Sf 12-20 lipoprotein.

No attempt was made to compare the relative effectiveness of the "atherogenic index" (24) with the results of the electrophoretic procedures in 
segregating normals from atherosclerotics since the "atherogenic index" is essentially a measure of total beta lipoprotein in terms of refractive index, with added weight placed on beta lipoproteins of lower density, and does not appear to provide very different information from the total beta lipoprotein concentration as measured by the electrophoretic techniques.

\section{DISCUSSION}

A summary is given in Table IV of the values obtained by various workers for the per cent of the total cholesterol or stainable lipid in the alpha lipoprotein fraction of sera from control and presumably atherosclerotic populations: In each case the data for normal males in the "coronary age group" have been compared to the data reported for atherosclerotic patients, when possible of the same sex and age. The results obtained in the present study on both control and atherosclerotic groups agree closely with the cholesterol analyses of Nikkilä (4), who used a paper electrophoretic method for lipoprotein separation, and of Barr, Russ, and Eder $(2,3)$ who used protein precipitation procedures. There is considerably more vari-

TABLE IV

A summary of data from various sources on the distribution of serum lipoproteins from "normal" and atherosclerotic individuals

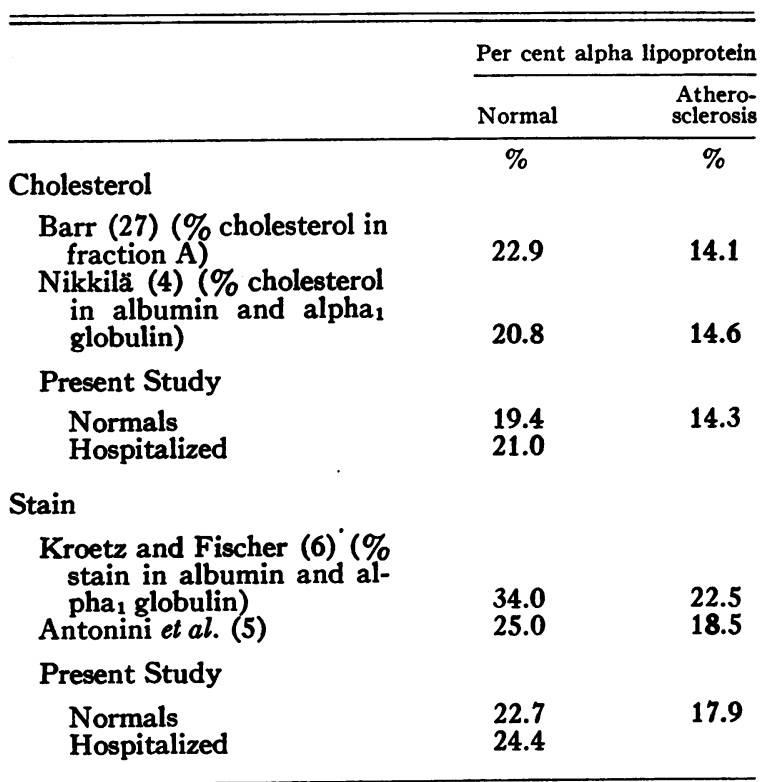

ation in the results of different laboratories when lipoprotein concentration is measured by lipid dye binding, although the results of published studies agree in the finding that the fraction of alpha lipoprotein is lowered in atherosclerotic populations. This variation is not unexpected in view of the different staining techniques used in different laboratories, and serves to emphasize the necessity for careful evaluation of the validity and reproducibility of the procedure itself, and the analysis of control sera at the same time and under the same conditions as experimental sera if meaningful results are to be obtained with such techniques.

The most serious difficulties encountered in studies of the relationship of lipoprotein levels to atherosclerosis are the absence of a method to determine the presence or absence of atherosclerosis in the "normal" subject during life and the difficulty of selecting control and experimental groups which differ only in their incidence of atherosclerosis. It is probably reasonable to assume that a group of patients with proved myocardial infarction will have definite atherosclerosis (25), but the incidence of atherosclerosis in clinically normal males of comparable age, which is probably well over 50 per cent (26), means that any measurement which is in fact associated with atherosclerosis will show a considerable overlap between control and atherosclerotic populations. The data obtained in the present study are shown in the form of scatter diagrams in Figures 3 and 4 to emphasize this overlap, which is not immediately apparent from inspection of the mean values and the statistical significance of their differences (Table I). That the observed differences between control and atherosclerotic groups are in fact associated with atherosclerosis and not some other difference between the groups is strongly suggested, although still not conclusively proven, by the finding that significant alterations of lipoprotein levels did not occur in a control group of patients hospitalized for illnesses not associated with atherosclerosis. Finally, it should be kept in mind that a correlation between any two variables, such as atherosclerosis and the level or distribution of serum lipoproteins, provides no proof of any casual relationship between the variables, but can only serve as an indication of an association between them and suggest paths for further investi- 
gation of abnormal metabolic pathways to establish any causal relationship.

\section{SUMMARY}

1. A standardized staining technique for the estimation of serum lipoproteins separated by paper electrophoresis gave results which were comparable to the results of cholesterol determinations on these lipoproteins and to the results of ultracentrifugal analysis of lipoproteins at a density of 1.21 .

2. No appreciable difference in lipoprotein concentration or distribution, measured by paper electrophoretic techniques, was found between the sera of 68 healthy male Army officers and the sera of 65 patients hospitalized with diseases not known to be associated with atherosclerosis or abnormalities in lipid metabolism.

3. Analyses of sera from 77 males with atherosclerosis, as judged by a history of myocardial infarction, showed a significant drop in alpha lipoprotein and increase in beta lipoprotein, resulting in a decreased ratio of alpha to total lipoprotein in these sera as compared to the control groups. Elevations in total cholesterol and total lipid dye binding capacity were less significant.

4. The percentage of the total serum cholesterol in the alpha lipoprotein fraction was lower in sera from patients studied from 0 to 6 months than in those studied over 6 months after an acute episode of myocardial infarction.

5. The electrophoretic distribution of serum proteins showed greater deviations from normal in the group of hospitalized patients than in the atherosclerotic group.

6. Ultracentrifugal analyses of lipoproteins of Sf 12-20 were less often abnormal than were electrophoretic analyses of the ratio of alpha to total lipoprotein in sera from atherosclerotic individuals.

\section{ACKNOWLEDGMENTS}

The authors are greatly indebted to the Medical Service of Walter Reed Army Hospital, the Base Hospital of the Bolling Air Force Base, the U. S. Army Hospital at Fort Belvoir and the Dispensary at the Pentagon for their cooperation in providing serum specimens, and to Mr. Fredoon Nury, Mr. Clarence Lockett, and Mr. Albert Lafayette for technical assistance in various phases of this investigation.

\section{REFERENCES}

1. Gofman, J. W., Jones, H. B., Lindgren, F. T., Lyon, T. P., Elliott, H. A., and Strisower, B., Blood lipids and human atherosclerosis. Circulation, $1950,2,161$.

2. Russ, E. M., Eder, H. A., and Barr, D. P., Proteinlipid relationships in human plasma. I. In normal individuals. Am. J. Med., 1951, 11, 468.

3. Barr, D. P., Russ, E. M., and Eder, H. A., Proteinlipid relationships in human plasma. II. In atherosclerosis and related conditions. Am. J. Med., 1951, 11, 480.

4. Nikkilä, E., Studies on the lipid-protein relationships in normal and pathological sera and the effect of heparin on serum lipoproteins. Scandinav. J. Clin. \& Lab. Invest., 1953, 5, Suppl. 8.

5. Antonini, F. M., et al. Lipoproteine ed eparina nel quadro umorale della chemiopatogenesi dell' aterosclerosi. Giorn. Gerontol., 1953, Suppl. 1.

6. Kroetz, C., and Fischer, F. W., Zur Blutchemie der akuten fortschreitenden Arteriosklerose. Elektrophoretische Lipoproteinbestimmungen bei Atheromatose und Atherosklerose. Deutsche med. Wchnschr., 1954, 79, 653.

7. Langan, T. A., Durrum, E. L., and Jencks, W. P., Paper electrophoresis as a quantitative method: Measurement of alpha and beta lipoprotein cholesterol. J. Clin. Invest., 1955, 34, 1427.

8. Jencks, W. P., and Durrum, E. L., Paper electrophoresis as a quantitative method: The staining of serum lipoproteins. J. Clin. Invest., 1955, 34, 1437.

9. Williams, F. G., Jr., Pickels, E. G., and Durrum, E. L., Improved hanging-strip paper-electrophoresis technique. Science, 1955, 121, 829.

10. Jencks, W. P., Jetton, M. R., and Durrum, E. L., Paper electrophoresis as a quantitative method. Serum proteins. Biochem. J., 1955, 60, 205.

11. Ray, B. R., Davisson, E. O., and Crespi, H. L., Experiments on the degradation of lipoproteins from serum. J. Phys. Chem., 1954, 58, 841.

12. Oncley, J. L., and Gurd, F. R. N., The lipoproteins of human plasma in Tullis, J. L., Blood Cells and Plasma Proteins. Their State in Nature. New York, Academic Press, 1953, p. 337.

13. Gordon, R. S., Jr., Interaction between oleate and the lipoproteins of human serum. J. Clin. Invest., $1955,34,477$.

14. Sperry, W. M., and Webb, M., A revision of the Schoenheimer-Sperry method for cholesterol determination. J. Biol. Chem., 1950, 187, 97.

15. Durrum, E. L., and Gilford, S. R., Recording integrating photoelectric and radioactive scanner for paper electrophoresis and chromatography. Rev. Scient. Instruments, 1955, 26, 51.

16. Gornall, A. G., Bardawill, C. J., and David, M. M., Determination of serum proteins by means of the biuret reaction. J. Biol. Chem., 1949, 177, 751.

17. U. S. National Advisory Heart Council. Technical Group of the Committee on Lipoproteins and 
Atherosclerosis, Lipoproteins and ultracentrifugal technique, a Symposium, 1952.

18. Lewis, L. A., and Page, I. H., Electrophoretic and ultracentrifugal analysis of serum lipoproteins of normal, nephrotic, and hypertensive persons. Circulation, 1953, 7, 707.

19. de Lalla, O. F., and Gofman, J. W., Ultracentrifugal analysis of serum lipoproteins. Methods of Biochemical Analysis, 1954, 1, 459.

20. Boyle, E., Bragdon, J. H., and Brown, R. K., Role of heparin in in vitro production of alpha, lipoproteins in human plasma. Proc. Soc. Exper. Biol. \& Med., 1952, 81, 475.

21. Fisher, R. A., Statistical Methods for Research Workers. 11th ed., Edinburgh, Oliver and Boyd, 1950.

22. Jencks, W. P., Smith, E. R. B., and Durrum, E. L., The clinical significance of the analysis of serum protein distribution by filter paper electrophoresis. Am. J. Med., In press.

23. Leinwand, I., and Moore, D. H., Serum lipid and protein fractions. IX. Comparisons of ninety-six patients with vascular disease and sixty normal controls (with additional notes on blood donors). Circulation, 1954, 10, 94.

24. Gofman, J. W., Glazier, F., Tamplin, A., Strisower, B., and de Lalla, O., Lipoproteins, coronary heart disease, and atherosclerosis. Physiol. Rev., 1954, 34, 589.

25. Yater, W. M., Traum, A. H., Brown, W. G., Fitzgerald, R. P., Geisler, M. A., and Wilcox, B. B., Coronary artery disease in men eighteen to thirtynine years of age. Report of eight hundred sixtysix cases, four hundred fifty with necropsy examinations. Am. Heart J., 1948, 36, 334, 481, and 683.

26. Enos, W. F., Holmes, R. H., and Beyer, J., Coronary disease among United States soldiers killed in action in Korea. Preliminary report. J. A. M. A., 1953, 152, 1090.

27. Barr, D. P., The George E. Brown Memorial Lecture. Some chemical factors in the pathogenesis of atherosclerosis. Circulation, 1953, 8, 641. 